\title{
Projeto Óleos Essenciais: extração, importância e aplicações no cotidiano
}

\author{
Essential oils oroject: extraction, importance and aplications in the \\ everyday
}

Marcelo Delena Trancosoํㅣ | marcelodt@uol.com.br

\section{RESUMO}

Óleos essenciais podem ser extraídos de vegetais que possuam óleos voláteis aromatizados. A técnica mais comum de extração é a destilação por arraste a vapor. Sabendo disso desenvolvemos este projeto, que visa motivar os alunos ao estudo das disciplinas científicas, mostrar a importância das ciências e contribuir para desmistificar o ensino de química. Selecionamos quatro alunas do Ensino Médio para divulgar o projeto e ministrar aulas experimentais para outras séries, sobre extração de óleos essenciais. Nossos propósitos têm sido atingidos. Observamos grande motivação e interesse em aprender por parte das alunas que trabalham no projeto, tanto na parte teórica quanto na parte experimental.

Palavras-chave: Arraste a vapor; extração; essências.

\section{ABSTRACT}

Essential oils can be extracted from vegetables that have volatile flavored oils. The most common extraction technique is steam distillation. Knowing this, we developed this project, which aim to motivate students to study science subjects, show the importance of the sciences and contribute to demystify the chemistry teaching. We selected four high school students to disclose the project and teach the experimental classes to other grades about the extraction of essential oils. Our purposes have been reached. We observed great motivation and interest in learning by the students who work on the project, both in theoretical and experimental part.

Keywords: Steam distillation; extraction; essences.

1 CBNB - Colégio Brigadeiro Newton Braga, Rio de Janeiro, RJ. 


\section{INTRODUÇÃO}

Óleos essenciais são compostos aromáticos, voláteis que podem ser extraídos de raízes, caules, folhas, flores ou de todas as partes de plantas aromáticas. Essas extrações podem ocorrer por destilação de arraste a vapor, que é a técnica mais empregada, compressão de vegetais ou uso de solventes (Métodos de Extração dos Óleos Essenciais, 2010).

Esses óleos possuem grande importância industrial e são empregados nas indústrias de perfumaria, cosmética, alimentícia e farmacêutica, sendo geralmente os componentes de ação terapêutica de plantas medicinais.

Algumas substâncias presentes nos óleos essenciais possuem alto valor comercial, neste caso, essas substâncias podem ser isoladas do óleo ou mesmo sintetizadas em laboratório, o mentol das espécies de mentha é um exemplo disso.

Vale ressaltar que nem todos os óleos essenciais possuem aroma agradável e nem sempre as espécies que os contem apresentam propriedades terapêuticas.

Quimicamente falando, óleo essencial é um óleo natural, com odor distinto, segregado pelas glândulas de plantas aromáticas, obtido por processo físico e estrutura química formada por carbono, hidrogênio e oxigênio, dando origem a complexa mistura de substâncias, que podem chegar a várias centenas delas, havendo predominância de uma a três substâncias que caracterizam a espécie vegetal em questão. Essas substâncias apresentam estruturas diversas como ácidos carboxílicos, alcoóis, aldeídos, cetonas, ésteres, fenóis e hidrocarbonetos dentre outras, cada qual com sua característica aromática e ação bioquímica (Wolffenbüttel, 2007).

Contudo sua principal característica consiste na volatilidade que o difere dos óleos fixos, que são misturas de substâncias lipídicas obtidas normalmente de sementes como óleo de soja, mamona, girassol, etc. (Farmacognosia, 2013).

\section{Breve Histórico dos Óleos Essenciais}

\section{- No Mundo}

Acredita-se que os primeiros usos dos óleos essenciais tenham sido através de bálsamos, ervas aromáticas e resinas que eram usadas para embalsamar cadáveres em cerimônias religiosas há milhares de anos atrás.

Existem relatos do uso de essências pelos chineses, em 2700 a.C, no mais antigo livro de ervas do mundo, Shen Nung que cita plantas como gengibre e ópio. Outro uso documentado de óleos essências se deu em 2000 a.C. em livros escritos em sânscrito, pelos hindus. Nessa época, já havia um conhecimento mais rudimentar de aparatos de destilação e há relatos de outros povos que fizeram uso desses compostos, como persas e egípcios. Muitas das ervas comuns na atualidade já eram conhecidas, como, por exemplo, o capim limão que era empregado em cerimônias religiosas ou fins terapêuticos (Lista de Óleos, 2013).

Durante as Cruzadas, o conhecimento se difundiu entre os árabes, que em pouco tempo aperfeiçoaram técnicas e aparatos de destilação. O que conferiu ao físico árabe Avicena (980 - 1073) o mérito de ser o primeiro a extrair óleo de rosas. Os árabes foram mestres na alquimia e, não por acaso, são conhecidos naquele momento da história como bem aperfeiçoados na medicina e terapias naturais (Lista de Óleos, 2013).

Somente em 1558 o italiano, Giovanni Battista della Porta (1535 - 1615), documentou uma forma de separar os óleos essenciais que até então eram apenas soluções alcoólicas, publicando o Magiae naturalis sive de miraculis rerum naturalium, uma obra de compilação, não com base em sua própria pesquisa, mas com estudo 
de autores antigos e modernos que trata da ciência popular, cosmologia, geologia, produtos vegetais, medicamentos, venenos, destilação, cométicos, pólvora, criptografia e outros temas (Wikipedia, 2013).

A partir dos séculos XVI e XVII, devido ao nível de tecnologia, maior conhecimento, exploração de suas propriedades e divulgação, a comercialização destes óleos se tornou mais popular pelo mundo. Não se deve esquecer que as especiarias, muitas delas ervas aromáticas de grande valor econômico, eram produtos valiosos na Europa.

Em 1928 o químico francês René-Maurice Gattefossé, criou o termo "aromoterapia”, associado a óleos essenciais, ficando conhecido como "pai da aromoterapia”. Fazendo uma destilação em seu laboratório, o químico sofreu um acidente tendo seus braços seriamente queimados. Em pânico, mergulho-os em uma tina de lavanda, que pensava ser água. Notou que em poucos minutos sua dor havia passado e dias mais tarde, não tinha mais cicatrizes. A partir daí, Gattefossé, passou a explorar as propriedades curativas desses extratos, ao contrário de antes, que só os usava como perfumes para seus produtos e criações (Wikipedia, 2013).

Deve-se também a este químico, um dos primeiros relatos de que produtos sintéticos que imitavam essências naturais tendiam a não ter as mesmas propriedades curativas. Hoje sabemos que como os óleos compreendem misturas complexas, a síntese e adição de substâncias puras aos preparados obviamente não deve produzir o mesmo efeito.

\section{- No Brasil}

Um dos primeiros produtos explorados no Brasil para extração de óleos essenciais foi retirado do pau -rosa, uma árvore da Amazônia, cuja essência, o óleo de linalol, tem aroma agradável. Essa essência, muito utilizada na indústria de perfumaria é matéria-prima do perfume Chanel $\mathrm{n}^{\circ} 5$ e de vários perfumes europeus e americanos (Chanel nº 5, 2000).

Sua exploração foi tamanha que até os dias atuais o Instituto Brasileiro do Meio Ambiente e dos Recursos Naturais Renováveis IBAMA colocou essa planta na lista de espécies em perigo de extinção. Outros vegetais também foram explorados, como o eucalipto, capim limão, menta, laranja, canela e sassafrás (Ela Não Sabia, 2013).

Devido a uma dificuldade de importar essências, uma maior demanda mundial pela produção brasileira ocorreu durante a segunda grande guerra, que foi ocasionada pela dificuldade dos países do ocidente de conseguir esses produtos de seus fornecedores habituais. Assim, o Brasil teve a maior parte de suas vendas voltadas para a exportação, o que ajudou significativamente no aumento da produção. Na década de 50 , empresas internacionais produtoras de perfumes, cosméticos, produtos farmacêuticos e alimentares se instalaram no país, ocorrendo o aumento da extração de essências no Brasil (Wikipedia, 2013).

Devido à importância dos óleos essenciais, resolvemos desenvolver este trabalho com nossos alunos, visando além de mostrar essa importância, demonstrar um dos processos empregados na extração de essências, estimular a exploração de temas transversais através da história dos óleos essenciais, como prevê os Parâmetros Curriculares Nacionais do Ensino Médio (PCNEM), divulgar a pesquisa na área científica, dentre outros.

\section{OBJETIVOS}

- Extrair óleos essenciais de plantas aromáticas;

- Observar aromas;

- Executar técnicas de laboratório; 
- Motivar e incentivar quanto ao estudo das disciplinas científicas;

- Promover interação com outras disciplinas;

- $\quad$ Mostrar a importância da pesquisa;

- Contribuir para desmistificar o ensino de química.

\section{METODOLOGIA}

O projeto está sendo desenvolvido no Colégio Brigadeiro Newton Braga - CBNB, teve início em março de 2013 e tem como participantes quatro alunas e um Professor de Química que coordena os trabalhos.

\section{Para selecionar os alunos para participarem do projeto, criamos os seguintes critérios:}

- pertencer à primeira série do Ensino Médio;

- $\quad$ ser voluntário para participar do projeto;

- estar matriculado no turno da manhã;

- $\quad$ preferencialmente, desejar cursar, a nível superior, algumas das áreas que tenha a Química como disciplina básica (Engenharia Química, Química Industrial, Farmácia, etc).

\section{Dessa forma, selecionamos as seguintes alunas:}

- $\quad$ Beatriz Alves Vieira Baptista;

- $\quad$ Gabriela Alves Gomes;

- $\quad$ Mylena Maciel Gonzalez; e

- $\quad$ Thayane Borges Ribeiro.

A essas alunas o professor coordenador do projeto, ministrou aulas teóricas e práticas sobre extração de essências, no laboratório de química. Após essas aulas, as alunas passaram a manipular as vidrarias, substâncias químicas e produzir essências, sempre sob a supervisão do professor. Essas atividades ocorrem sempre no turno da tarde, para que as alunas não deixem de assistir às aulas de outras disciplinas.

Visando divulgar o trabalho, a utilização de óleos essenciais e também, a importância da química, pretendemos que as alunas que participam do projeto, ministrem aulas sobre a extração de óleos essenciais, para alunos de outras séries, no próprio laboratório de química.

Para extração dos óleos essenciais, escolhemos a destilação por arraste a vapor, método mais difundido, empregado para separar misturas imiscíveis ou seja, não se dissolvem em água, por serem substâncias apolares. Os componentes de uma mistura imiscível “fervem” a temperaturas menores do que os pontos de ebulição dos componentes individuais. Assim, uma mistura de compostos de alto ponto de ebulição e água, pode ser destilada à temperatura menor que $100^{\circ} \mathrm{C}$, ponto de ebulição da água (O Mundo Mágico dos Aromas, 2013). 
No experimento, a água é aquecida num frasco de kitassato (gerador de vapor). O vapor resultante é "bombeado" sob pressão, para outro recipiente (balão de destilação) que contem a mistura a ser destilada (água mais vegetal). O calor do vapor faz com que as paredes das células da planta se abram, liberando o óleo que evapora junto com a água. A pressão do vapor d'água "arrasta” a substância a ser extraída para um condensador, acoplado ao balão de destilação, condensando e sendo recolhido em um becher. Como o óleo essencial é uma substância apolar, ele não se mistura com a água, que é substância polar. Por ter densidade menor que $1,0 \mathrm{~g} / \mathrm{cm}^{3}$, o óleo fica concentrado sobre a camada de água $\left(\mathrm{d}=1,0 \mathrm{~g} / \mathrm{cm}^{3}\right)$, podendo ser separados com o uso de um funil de separação.

A extração não ocorre por aquecimento direto da mistura a ser destilada (água mais vegetal), pois nesse caso a mistura seria cozida e não extrairíamos o óleo essencial, tal como acontece na preparação de chás por exemplo.

\section{Vidrarias, equipamentos e substâncias necessárias:}

- 1 balão de destilação de 500 mL;

- 1 condensador de vidro de tubo reto;

- 1 kitassato de $500 \mathrm{~mL}$;

- 1 becher de $250 \mathrm{~mL}$;

- 1 tubo de vidro para conectar o kitassato ao balão de destilação;

- 1 tubo de vidro para ser empregado como tubo de segurança;

- 1 bico de Bunsen;

- e pistilo;

- 3 suportes universais;

- 5 garras;

- mangueiras para conexões;

- rolhas;

- 2 telas de amianto;

- 20 a 40 gramas do vegetal a ser destilado;

- $380 \mathrm{~mL}$ de água.

\section{Montagem da aparelhagem e preparação para extração:}

- montar a aparelhagem conforme mostra a figura I;

- com auxílio do almofariz e pistilo, triturar a massa do vegetal, misturar com $80 \mathrm{~mL}$ de água e transferir para o balão de destilação; 
- $\quad$ conectar as mangueiras ao destilador e ao kitassato;

- $\quad$ conectar a mangueira do condensador a uma torneira;

- $\quad$ ao kitassato adicionar $300 \mathrm{~mL}$ de água, encaixar a rolha com o tubo de segurança e iniciar o aquecimento, com o bico de Bunsen, até a ebulição;

- $\quad$ observar atentamente e constantemente, se não existe vazamento de vapor;

- aguardar o início da destilação; e

- observar o aroma do óleo extraído.

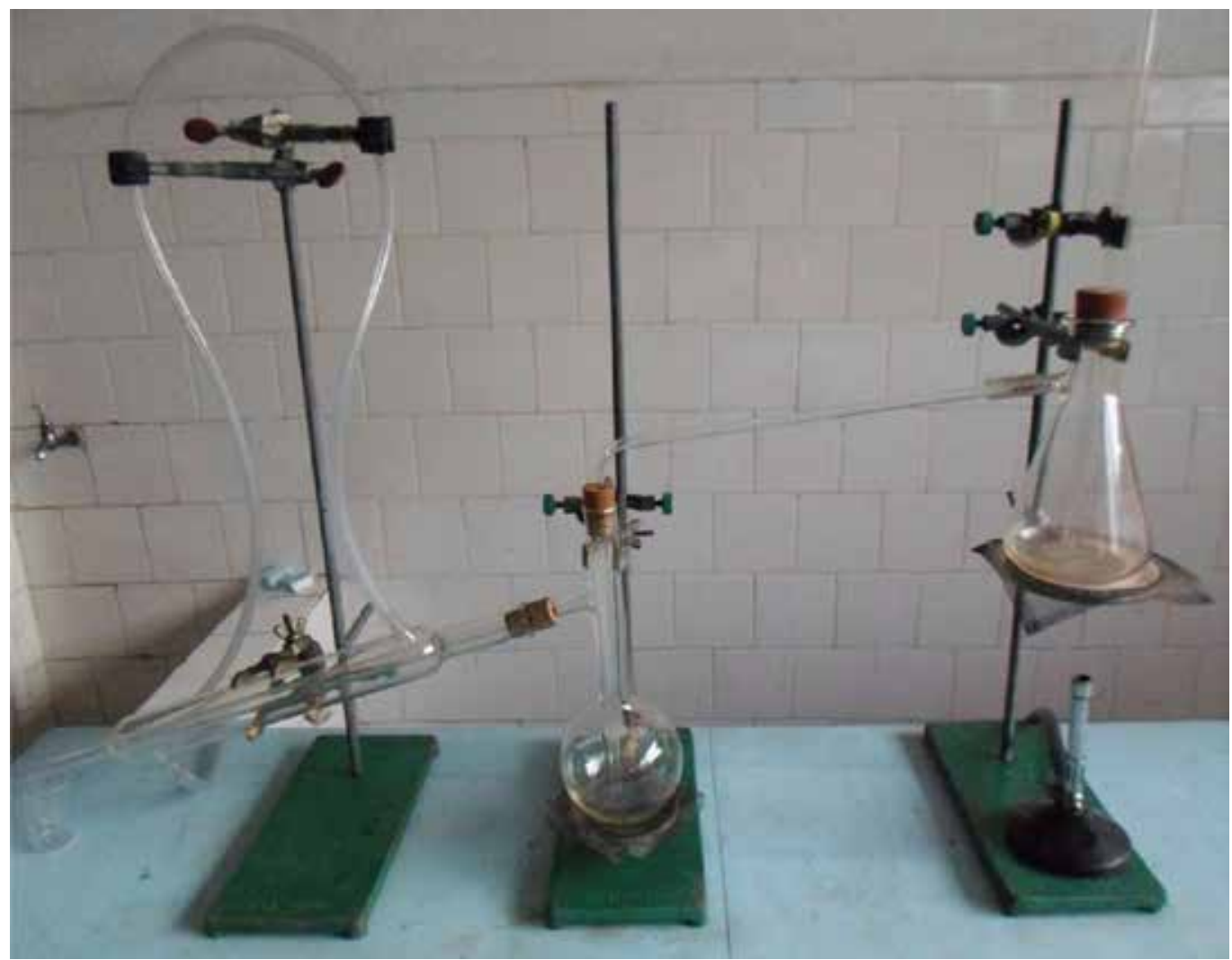

Figura I

\section{RESULTADOS ESPERADOS}

Extraímos essências do cravo da índia, canela em pau, cascas de laranja e limão, percebemos a mistura óleo e água, coletadas no becher e seus aromas característicos.

O vapor d'água formado "arrastou" os óleos essenciais dos vegetais destilados, condensando quando entrou em contato com a parte resfriada do condensador.

Observamos que o rendimento dessas extrações é muito baixo, cerca de $20 \mathrm{~mL}$ e que, para prepararmos um volume considerável, temos que ter uma quantidade muito superior a massa de vegetais empregada que foi de 30 gramas. Isso demandaria um tempo muito maior de trabalho, além de requerer vidrarias com maior capa- 
cidade, que não possuímos em nosso laboratório, porém, como nosso intuito não é produzir óleos essenciais em grandes quantidades, julgamos que o projeto já está atingindo alguns de seus objetivos.

Observamos que as alunas participantes do trabalho, estão motivadas para as atividades, participam de todas as etapas do processo e se mostram interessadas em aprender tudo o que é ensinado, seja nas aulas teóricas ou práticas. Realizam técnicas de laboratório necessárias à extração de óleos essenciais, mostrando inclusive uma boa desenvoltura na montagem da aparelhagem e manuseio das vidrarias.

Vamos realizar extração de óleos essenciais de outros vegetais, como camomila, erva doce, etc, visando que as alunas adquiram maior segurança na parte experimental e também na retórica, para que no dia 28 de maio, sejam iniciadas as aulas experimentais que elas irão ministrar para outras séries. Inicialmente começaremos com turmas do primeiro segmento e posteriormente as demais séries.

Será a primeira vez que alunos do primeiro segmento irão ao laboratório de química. Esperamos que além de conhecerem um pouco da importância das ciências, adquiram interesse pelo estudo das disciplinas científicas, uma vez que verão alunas do mesmo colégio, vestindo os mesmos uniformes que eles, trabalhando com vidrarias, fogo e realizando experimentos químicos.

\section{CONCLUSÃO}

Qualquer vegetal que possua óleos voláteis aromatizados pode ser utilizado como matéria-prima para a extração de óleos essenciais.

A técnica de destilação por arraste a vapor não apresenta dificuldade na montagem da aparelhagem nem durante o processo de extração, contudo requer cuidados devido à utilização do fogo, líquidos em ebulição, vidrarias quentes, etc.

As alunas participantes do projeto mostram-se muito motivadas nas atividades realizadas, apresentando interesse mais acentuado na execução das atividades experimentais e sugerindo melhorias para os trabalhos. Divulgam o projeto nas salas de aula e convidam os alunos para conhecer as atividades no laboratório de química. Criaram um logotipo para o projeto e sugeriram que fosse colocado na camisa do colégio, visando maior divulgação do trabalho. Levamos essa sugestão à direção, que aprovou a ideia. As camisas estão em processo de confecção com previsão de entrega em 20 de maio.

Vamos desenvolver o projeto durante todo o ano letivo, bem como inscrevê-lo em simpósios, feiras de ciências e outros eventos. Assim, teremos um tempo maior e mais oportunidades para divulgá-lo, mostrando a importância das ciências e tentando motivar um número maior de alunos ao estudo das disciplinas científicas. 


\section{REFERÊNCIAS BIBLIOGRÁFICAS}

BRASIL, Ministério da Educação, Secretaria de Educação Média e Tecnológica. Parâmetros Curriculares Nacionais do Ensino Médio - PCNEM. Ministério da Educação. Secretaria de Educação Média e Tecnológica. Brasília: Ministério da Educação, 1999.

ELA NÃO SABIA (2013), Disponível na internet (http://www.revistaecologico.com.br/. acesso em março 2013).

FARMACOGNOSIA (2013), Disponível na internet (http://www.ebah.com.br. Acesso em março de 2013).

LISTA DE ÓLEOS (2013), Disponível na internet (http://www.ervadocecosmeticos.xpg.com.br/8.html. acesso em abril de 2013).

MÉTODOS DE EXTRAÇÃO DOS ÓLEOS ESSENCIAIS (2012), Disponível na internet (http:// oleosessenciaisnaturais.blogspot.com.br. acesso em abril de 2013).

O MUNDO MÁGICO DOS AROMAS (2013), Disponível na internet (http://www.jardimdeflores.com.br. acesso em março 2013).

Chanel nº 5 (2000), Disponível em (http://veja.abril.com.br. acesso em abril de 2013).

WIKIPEDIA (2013), Disponível na internet (http://pt.wikipedia.org/wiki/Óleo_essencial. acesso em março de 2013).

WIKIPEDIA(2013), Disponível na internet (http://pt.wikipedia.org/wiki/Giovanni_Battista_della_Porta. acesso em abril 2013)

WOLFFENBüTTEL, Adriana Nunes. Óleos essenciais. Informativo CRQ-V, ano XI, n. ${ }^{\circ} 105$, págs. 06 e 07 novembro/dezembro/2007. 